\title{
A pilot study on palmyrah pinattu (dried fruit pulp) as an anti-diabetic food component
}

\author{
Inoka ULUWADUGE ${ }^{1,2^{*}}$, Antoinette PERERA ${ }^{1}$, Errol JANSZ $^{1}$ and Ira THABREW ${ }^{2}$ \\ ${ }^{1}$ University of Sri Jayewardenepura, Gangodawille, Nugegoda. Sri Lanka. \\ ${ }^{2}$ University of Kelaniya, Ragama, Sri Lanka. \\ *Corresponding author, E mail: deepthi_uluwaduge@yahoo.com
}

\begin{abstract}
The fruit pulp of palmyrah (Borassus flabellifer L.) has been shown to inhibit intestinal glucose uptake in mice, the active principle being a steroidal saponin, flabelliferin-II which inhibits intestinal ATPase in mice at $5 \times 10^{-5} \mathrm{M}$ level. Palmyrah fruit pulp (PFP) is widely used to manufacture many food products including dried PFP (pinattu), which has been consumed in North-East Sri Lanka for centuries. The present study was carried out to investigate whether PFP in the form of pinattu could reduce serum glucose levels of mild diabetic (TypeII) patients who were not on a drug regimen with a view to developing pinattu as an anti-diabetic food component. Patients (newly diagnosed, Type-II, mild diabetic patients) attending the diabetic clinic at the Family Practice Centre, University of Sri Jayewardenepura, Sri Lanka, were subjected to a glucose challenge (75 g/50 kg BW) after a 10 hour overnight fast and the blood glucose levels determined. On subsequent visits of each patient (3 days after the first visit) blood glucose was determined after administration of PFP in the form of pinattu (6 g/50 kg BW) or fibre $(4 \mathrm{~g} / 50 \mathrm{~kg} \mathrm{BW})$ extracted from PFP prior to the glucose challenge. The methodology employed was the cross over method where each patient was its own control. In all mild diabetic patients treated with pinattu, there was a significant reduction $(\mathrm{p}<0.01$, by $15-48 \%)$ in blood glucose concentration after a glucose challenge. Therefore the results of the present study suggest that pinattu (dried PFP) could be used as an anti-hyperglycemic agent.
\end{abstract}

(C) 2007 International Formulae Group. All rights reserved.

Key words: Borassus flabellifer, flabelliferin, palmyrah fruit pulp, blood glucose, diabetes.

\section{INTRODUCTION}

Palmyrah (Borassus flabellifer L, Family: Arecaceae) is present in the arid zone of India, Sri Lanka South and East Asia and African countries (Thabrew and Jansz, 2004). The fruit of this dioceous palm contains a yellow-orange pulp (PFP) covering 1-3 seeds. The pulp contains pectin, sugar, carotenoids and numerous steroidal saponins (flabelliferins) (Thabrew and Jansz, 2004). One of these flabelliferins, a tetraglycoside of $\beta$-sitosterol (Ariyasena, 2002) termed F-II (Nikawala, 2000) was suspected to reduce weight gain in ICR mice (Ariyasena et al., 2002a). This reduced weight gain is reversed when the pulp is treated with the enzyme naringinase, which hydrolyses the bitter F-II and another flabelliferin- FB (triglycoside).
Feeding non-bitter PFP to mice (with FB but no F-II) caused no reduction in weight gain (Ariyasena et al., 2002b). These findings suggested that F-II has an effect on growth of mice.

More recent studies (Uluwaduge et al., 2005a) with mice have demonstrated that F-II (1 $\mathrm{mg} /$ mouse) extracted from PFP can significantly inhibit the expected increase in blood glucose after a glucose challenge, while enhancing the level of faecal glucose, thus suggesting an inhibition of intestinal glucose uptake (Uluwaduge et al., 2005a). The results of this study also indicated that inhibition of $\mathrm{Na}^{+} / \mathrm{K}^{+}$ATPase activity could be a mechanism by which F-II mediates its inhibitory action on intestinal glucose uptake in mice. 
Previous investigations carried out by the authors have also demonstrated that feeding 10\% PFP containing feed for one week (short term) or feeding $10 \%$ and $50 \%$ PFP containing feed for 30 days (long term) did not result in any significant toxic side effects (Uluwaduge et al., 2005b) .

Pinattu is a dried PFP, which has been eaten by people of the North-East of Sri Lanka for centuries; it is a pleasant flavored solid with a chewing gum like texture.

Since PFP has been demonstrated to be relatively non-toxic, the present study was undertaken to investigate whether PFP (in the form of pinattu) can be used as an antidiabetic food component.

\section{MATERIALS AND METHODS}

Preparation of pinattu (Nikawala, 2000)

PFP (600g) was dried in layers in a

11/2m x 21/2m Mitchell forced draft tray drier (Mitchell, USA) at $60{ }^{\circ} \mathrm{C}$ using one tray for about 40 hours in Indrustrial Technology Institute (ITI), Colombo, Sri Lanka. This was prepared under strict supervision and under hygienic conditions (no microbial and chemical contamination). Finally dried layers of PFP (pinattu) were cut into pieces (6 g each) and packed and sealed in polythene and stored at $-5{ }^{\circ} \mathrm{C}$.

\section{Extraction of fibre from PFP}

Dietary fibre was isolated from PFP (600 g) by an ethanol precipitation using a modification (omitting incineration) of the methods described by Asp et al. (1983).

\section{Extraction of bitter flabelliferin (F-II) from PFP}

F-II was extracted and purified by the method described previously by Jansz et al. (1994).

\section{Selection of human diabetic subjects}

Characteristics of patients selected for the study are shown in Table 1 . Patients ( $n=20,8$ male and 12 females, 45-60 years old and 45-55 kg BW) who attended the Family Practice Centre, Faculty of Medical Sciences, University of Sri Jayewardenepura, Nugegoda, Sri Lanka and were confirmed as type-II mild diabetics, and who consented to participate in the study were invited to enter the study. Since mild diabetics, may vary in their response to a glucose challenge, the cross-over method where each patient is its own control, was employed in this study.

Only those patients who were shown at their first visit to the clinic, to have fasting blood glucose level between 110- $200 \mathrm{mg} / \mathrm{dl}$ (mild, Type II diabetic or impaired glucose tolerance patients) and were not on any drug regimen were selected for the study. Ethical clearance for this study was obtained (No: 180) from the Ethics Committee, Faculty of Medical Sciences, University of Sri Jayewardenepura, Nugegoda, Sri Lanka.

\section{Glucose challenge, administration of pinattu and fibre to patients Glucose challenge}

Patients on the first visit to the diabetic clinic after $10 \mathrm{~h}$ fast were orally administered a dose of glucose (75 $\mathrm{g}$ of glucose dissolved in $300 \mathrm{ml}$ of water). One hour and thirty minutes after administration of the glucose, a sample of blood $(0.5 \mathrm{ml})$ was drawn by venepuncture for the determination of postprandial blood sugar (PPBS) by the glucose oxidase method (Hugget and Nixon, 1957). This was considered to be the control blood glucose value of each patient.

\section{Administration of pinattu}

Based on IC50 of intestinal ATPase by F-II (Uluwaduge et al., 2006), a dose of $6 \mathrm{~g}$ pinattu was selected for administration to diabetic patients. Three days after the 1 st visit, each patient (fasted for 10 hours) was given $6 \mathrm{~g}$ of pinattu 30 minutes prior to the glucose challenge. Blood was drawn (1.5 hours after the glucose load) for the determination of blood glucose as before. This was taken as the test sample.

\section{Administration of fibre}

Three days after the test samples were taken, each patient (10 hour fasting) was orally fed with a suspension of PFP fibre (equivalent to $6 \mathrm{~g}$ of pinattu, $4 \mathrm{~g}$ fibre $/ 100 \mathrm{ml}$ water), 30 min prior to the glucose load and blood was drawn for the determination of blood glucose as before. This was taken as the fibre control.

\section{Statistical analysis}

The difference between the postprandial blood glucose levels after each meal was compared using one way ANOVA. The differences between groups were determined using post hoc S-N-K test. 


\section{RESULTS}

The mean reduction in the blood glucose level of each subject brought about by pinattu (6 g) or PFP fibre (4 g) after a glucose challenge is summarized in Table 2 . The reduction of blood glucose mediated by pinattu or fibre in each mild diabetic patient included in the study is shown in Figure 1. The pinattu used in the study, contained 50 mg F-II per 6 g.
Statistical analysis showed that there was a significant difference between the postprandial blood glucose level at base line and after ingestion of pinattu ( $\mathrm{F}=11.9$, $\mathrm{p}<0.001$ ). There was no difference between the postprandial blood glucose levels at base line and after ingestion of fibre extracted from PFP.

Table 1: Characteristics of patients selected for the study.

\begin{tabular}{ll}
\hline Characteristic & Description \\
\hline (a) Gender & Male-8 \\
& Female-12 \\
(b) Age range & $45-65$ years \\
(c) Weight range & $45-55 \mathrm{~kg}$ \\
(d) Fasting blood glucose level & $110-200 \mathrm{mg} / \mathrm{dl}$ \\
(e) Any other systemic illness that needed & \\
$\quad$ treatment & No \\
(f) On anti-diabetic treatment at time of & \\
$\quad$ recruitment to the study & No \\
\hline
\end{tabular}

Table 2: Postprandial blood glucose level (PPBS) in type II diabetic patients $(n=20)$ with or without treatment of pinattu or PFP fibre.

\begin{tabular}{lcc}
\hline PPBS value & Mean PPBS (mg/d) & $\begin{array}{c}\text { Mean percentage reduction of in } \\
\text { comparison with baseline }\end{array}$ \\
\hline No treatment (base line) & $281.3 \pm 92$ & - \\
Pinattu (6 g) & $191 \pm 51.6$ & $28.6^{*}$ \\
Fibre (4 g) & $250.1 \pm 56.4$ & 5.9 \\
\hline
\end{tabular}

Mean \pm SEM; $\quad *$ Significantly different from the base line value $(\mathrm{p}<0.01)$

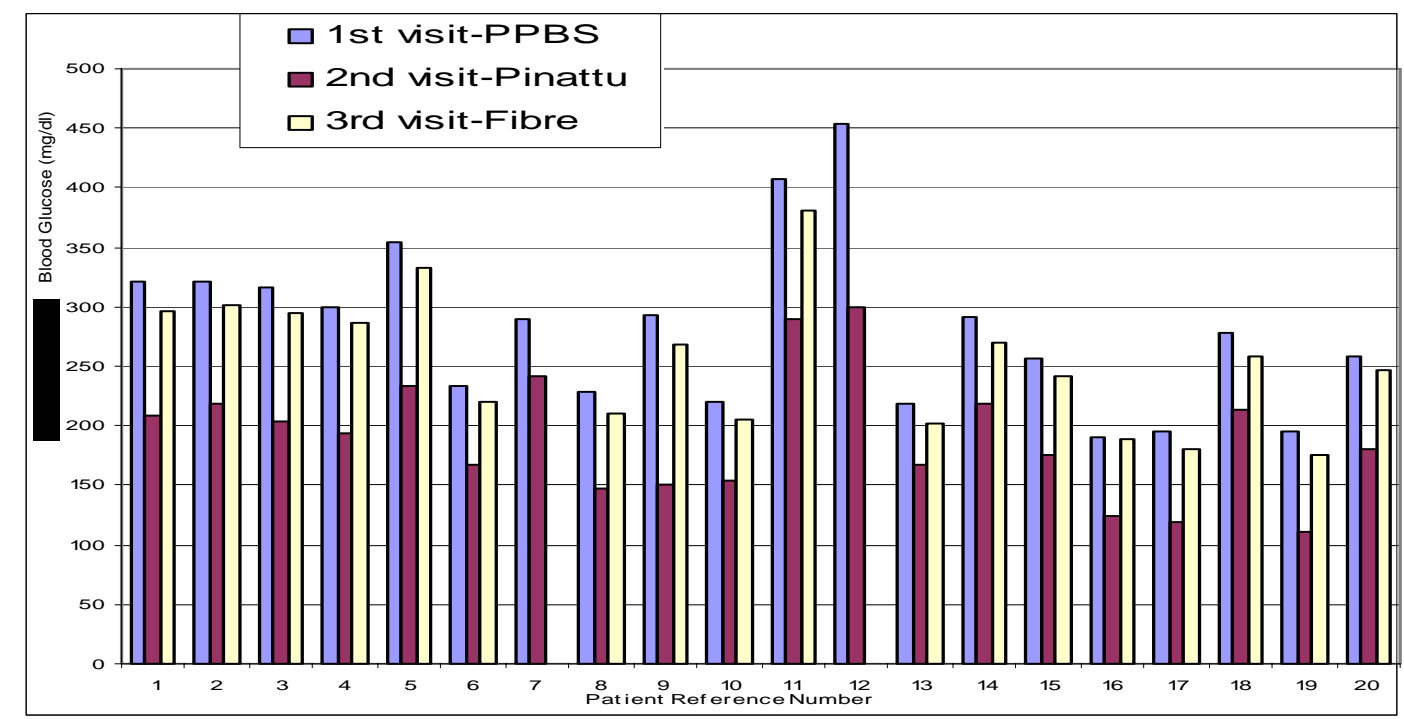

Figure 1: Postprandial blood glucose level $(\mathrm{mg} / \mathrm{dl})$ of each patient with or without treatment of pinattu and PFP fibre with respect to control values in individual patients $(n=20)$. Patient No. 7 and 12 did not report for crude fibre trial. 


\section{DISCUSSION}

Pinattu, a product prepared by drying PFP has been consumed by people of the North-East Sri Lanka for centuries with no documented evidence of toxicity (Thabrew and Jansz, 2004).

The present study was carried out to investigate whether PFP in the form of pinattu could reduce serum glucose levels of mild diabetic (Type-II) patients with a view to developing pinattu as an anti-diabetic food component. Results of the present study demonstrated that in mild, type-II diabetic patients administered with pinattu (6 g), there was a $15-48 \%$ reduction $(\mathrm{p}<0.05)$ in the blood glucose after a glucose challenge when compared with their own control values. These findings suggest that pinattu can help in the reduction of postprandial blood glucose levels of mild diabetic, type-II patients who are not under any other drug regimen.

Previous study by Uluwaduge et al. (2005a) showed that fresh PFP can reduce the postprandial blood glucose level of mice. The overall results of this study together with the findings of the present investigation provide confirmatory evidence for the presence of hypoglycemic components in PFP. The major chemical components in PFP are flabelliferins and fibre (Thabrew and Jansz, 2004). In the previous study with mice conducted by Uluwaduge et al. (2005a), it was shown that flabelliferin-II can inhibit intestinal glucose uptake. However, the effect of fibre was not evaluated. It is possible that the fibre in PFP can also contribute significantly to reduce blood glucose level.

It is well documented that fibre can reduce intestinal glucose absorption by modulating the absorption of carbohydrate in the small intestine (Wickramanayake, 1998). For example, Guar gum, which is a gel forming dietary fibre (a commercially separated product of the endosperm of the Indian-cluster bean, (Cyamopsis tetragonolobus) has been shown to be a factor which reduces the fasting blood sugar levels significantly in type II diabetics (Usithupa et al., 1990).

PFP contains $11.9 \mathrm{~g} / 100 \mathrm{~g}$ of total crude fibre (Sumudini, 2002). In the present study with type-II diabetic patients, oral administration of a suspension of fibre isolated from PFP resulted in a small (2-11\%) statistically non significant ( $p>0.05$ ) decline in the blood glucose (after glucose load) concentration when compared with their own control values.

From the results of the present study and previous study with mice (Uluwaduge et al., 2005a), the major inhibitory effect of pinattu on intestinal glucose absorption appears to be mediated by the flabelliferin fraction (flabelliferin-II) rather than the fibre contained in PFP.

Since the study with mice conducted by Uluwaduge et al. ( 2005a) has shown that F-II can inhibit intestinal glucose uptake by inhibition of the intestinal $\mathrm{Na}+\mathrm{K}+\mathrm{ATP}$ ase pump, and increase the faecal excretion of glucose, the same mechanisms may be responsible for the PFP mediated reduction in blood glucose levels in human diabetic subjects also. Therefore, PFP (pinattu) may have a special application in the control of blood glucose in obese diabetic patients and in the weight control of obese individuals in general. To obtain evidence for the above hypothesis, a further study that includes a larger number of diabetic patients has to be conducted. The study must be followed up by a full scale multi-centre clinical trial that will enable a better statistical evaluation of results. It may be concluded from results of the present study that pinattu reduces the postprandial blood glucose levels in all the patients included in this study and therefore has the potential to be used as an anti-diabetic agent.

According to information in published literature there is a remarkable increase in the diabetic population of the world. Therefore, if F-II from PFP can be developed into a suitable pharmaceutical drug, it could be of benefit not only to diabetic patients of Sri Lanka, but also to the diabetic population of the world. The weight reducing properties of F-11 may also be of benefit to patients suffering from cardio-vascular diseases.

\section{ACKNOWLEDGEMENTS}

The financial support by the IPICS SRI: 07 and NSF/RG/2001/07 is appreciated. The authors wish to thank the staff of the Family Practice Center, Faculty of Medical Sciences, University of Sri Jayewardenepura, Sri Lanka, and Mr. P. K. Attanayake, Dept. of Biochemistry, Faculty of Medical Sciences, 
University of Sri Jayewardenepura for technical assistance.

\section{REFERENCES}

Ariyasena DD. 2002. Diversity, bioactivity and structural studies on the flabelliferins of palmyrah (Borassus flabellifer L.) fruit pulp. M.Phil. Thesis, University of Sri Jayewardenepura, Nugegoda, Sri Lanka.

Ariyasena DD, Jayasekera S, Jansz ER, Abeysekera AM. 2002a. Effect of palmyrah (Borassus flabellifer L.) fruit pulp on weight gain by mice. Vidyodaya J. Sci., 9: 99-105.

Ariyasena DD, Jansz ER, Jayasekera S, Abeysekera AM. 2002b. Inhibitory effect of the bitter principle of palmyrah (Borassus flabellifer L.) fruit pulp on the growth of mice: evidence using bitter and non bitter fruit pulp. J. Sci. Fd. Agric., 80: 1763-1766.

Asp NG, Hallmerh CG, Siljestrom M. 1983. Rapid enzymatic assay for insoluble and soluble dietary fibre. J. Agri. Fd. Chem., 31: 476-482.

Hugget AStG. Nixon DA. 1957. Use of glucose peroxidase and dianisidine in the determination of blood and urinary glucose. Lancet II., 368-370.

Jansz ER, Nikawala JK, Goonaratne J, Theivendirarajah K. 1994. Studies on the bitter principle and debittering of palmyrah fruit pulp. J. Sci. fd. Agric., 65: 185-189.

Nikawala JK. 2000. Aspects of the chemistry and antimicrobial activity of flabelliferins of palmyrah fruit pulp. M.Phil. Thesis, University of University of Sri Jayewardenepura, Nugegoda, Sri Lanka.
Sumudini KAV. 2002. Some factors affecting the neurotoxic effect of palmyrah flour. M.Phil Thesis, University of Sri Jayewardenepura, Nugegoda, Sri Lanka.

Tissera MHA, Thabrew MI. 2001. Medicinal plants and Ayurvedic preparations containing medicinal plants used in the control of Diabetes Mellitus. Department of Ayurveda, Sri Lanka.

Thabrew MI, Jansz ER. 2004. Nutritive importance of palmyrah products. Recent research development. Environ. Biol., 1: 43-60.

Uluwaduge DI, Thabrew MI, Jansz ER. 2005a. The effect of flabelliferins of the palmyrah fruit pulp on intestinal glucose uptake in ICR mice. J. Natn. Sci. Foundation, 4: 37-41.

Uluwaduge DI, Thabrew MI, Jansz ER. 2005b. Preliminary report on the absence of toxicity of the fruit pulp palmyrah (Borassus flabellifer). J. Natn. Sci Foundation, 33: 37-41.

Uluwaduge DI, Keerthi AAP, Senadheera SN, Jansz ER. 2006. Studies on natural hydrophobic binder of flabelliferins and the effect on some bioactivities. J. Natn. Sci Foundation, 33: 187-191.

Uusithupa M, Sodervik H. Silvast M. 1990. Effects of a gel forming dietary fibre, guar gum, on the absorption of glibenclamide and metabolic control and serum lipids in patients with non-insulin dependent (Type II) diabetes. Inter. J. Clinical Pharm. Toxico., 28: 153-157.

Wickramanayake TW. 1998. Food and Nutrition (3rd edn). Hector Kobbekaduwa Agrigarian Research and Training Institute: Colombo, Sri Lanka. 